\title{
An Interdisciplinary Approach to the Sustainability of a Gravity-Fed Water System in the Peruvian Andes
}

\author{
Riley Wagner \\ Class of 2020, Chemical and Biological Engineering \\ Princeton University \\ Princeton, NJ 08544 \\ rileyws@princeton.edu \\ Sydney Hsu \\ Class of 2021, Mechanical and Aerospace Engineering \\ Princeton University \\ Princeton, NJ 08544 \\ sydneyh@princeton.edu \\ John Nicholas Kick \\ Class of 2020, Civil and Environmental Engineering \\ Princeton University \\ Princeton, NJ 08544 \\ jkick@princeton.edu \\ Sofia Bisogno \\ Class of 2020, Civil and Environmental Engineering \\ Princeton University \\ Princeton, NJ 08544 \\ sbisogno@princeton.edu \\ Camille Heubner \\ Class of 2020, Civil and Environmental Engineering \\ Princeton University \\ Princeton, NJ 08544 \\ cheubner@princeton.edu \\ Sneha Iyer \\ Class of 2020, Mechanical and Aerospace Engineering \\ Princeton University \\ Princeton, NJ 08544 \\ sgiyer@princeton.edu \\ Scott Overbey \\ Class of 2021, Economics \\ Princeton University \\ Princeton, NJ 08544 \\ poverbey@princeton.edu \\ Peter Jaffe \\ Professor, Civil and Environmental Engineering \\ Princeton University \\ Princeton, NJ 08544 \\ jaffe@princeton.edu
}


Abstract - This paper analyzes the methods used by the Princeton University Chapter of Engineers Without Borders to ensure the sustainability of a gravity-fed potable water system in rural northwestern Peru. While similar small scale development projects consider sustainability in their design process, some do not recognize the importance of an interdisciplinary approach to sustainability. This team, however, is inherently interdisciplinary in nature due to its unique subteam structure, which subsequently affects its approach to sustainability. By examining the technical, social, and financial considerations of the project conducted by the Princeton University Chapter of Engineers Without Borders, this paper argues for a three-pronged approach to sustainability. As can be seen through thoughtful design parameters, strong local partnerships, and strategic financial mechanisms, the project displays promise of future success with regards to sustainability. The main objective of the Princeton Chapter of Engineers Without Borders in this partnership is to ensure that the community has the knowledge, tools, and resources necessary to maintain the water system in a self-sufficient manner at the completion of the chapter's involvement.

Index Terms - Engineers Without Borders, Gravity-Fed Water System, International Development, Potable Water, Sustainability

\section{Team History ANd Project BaCkgRound}

Since its establishment in 2004, the Princeton University Chapter of Engineers Without Borders (EWB-Princeton) has partnered with communities in several developing countries to implement projects designed to improve the quality of life for their residents. Previous EWB-Princeton projects in Peru have involved installing latrines, solar lighting systems, cookstoves, and most recently, clean water distribution systems.

The Peru Team of EWB-Princeton is composed of approximately thirty students of various academic disciplines who design the system, organize logistics, and raise funds during the academic year. The team is organized into four subteams, each of which is tasked with a specific aspect of the project.

- Technical Team - design of the pipelines and system components

- Community Team - establishment of strong community relations through research, surveys, and frequent communication; development of household user manuals

- Finance Team - formulation of trip budgets and acquisition of funds through crowdfunding, grant writing, and seeking sponsorships

- Publicity Team - promotion of EWB-Princeton on and off campus through media and video production

For several weeks each summer, a team composed of two Project Managers, four team members, and a professional engineering mentor travels to the community to work on that specific stage of the project.

Currently, the Peru Team of EWB-Princeton is partnered with Pusunchás, an agricultural community located in the foothills of the Northern Peruvian Andes. Pusunchás has lacked access to reliable water for the past twenty-five years due to the source of the municipal water system drying up. The community repeatedly petitioned the local government to address the issue; however, due to a scarcity in municipal resources, no action was taken. Community members were left with few sustainable options. Common alternatives included walking many kilometers to fill 
up buckets from streams or collecting water in small pools during the rainy season to use as a source during the dry season. Unfortunately, these methods make the water more susceptible to potential contamination from human and animal waste and agricultural runoff and thus pose serious health risks to the community in addition to being generally unreliable.

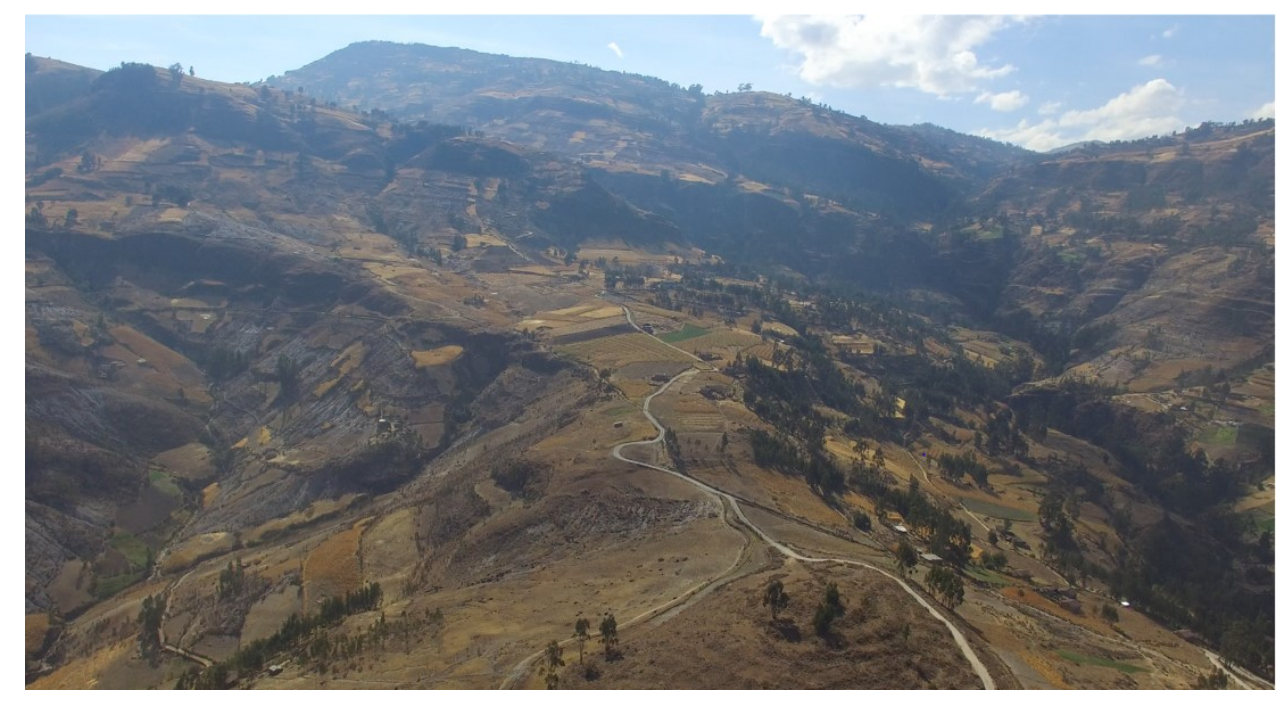

\section{FIGURE 1 \\ AERIAL SHOT OF THE COMMUNITY OF PUSUNCHÁS}

In order to address the issues and needs of the community, EWB-Princeton created a partnership agreement between the community leaders of Pusunchás and a local non-governmental organization (NGO), Las Marianistas, to facilitate the design and construction of a gravity-fed potable water system. Clean water collected from a natural spring would be distributed via pipeline network to every home in the community that elected to partake in the system. Servicing over 200 people across approximately thirteen square kilometers, this was the largest project that EWBPrinceton had ever embarked on and over three times larger than the previous project undertaken by the team. As per guidelines established by the EWB national chapter (EWB-USA), the project fits a five-year timeframe. The first year was dedicated to data collection and community assessment and was followed by three years of system implementation, culminating in a fifth and final year for evaluating and monitoring the completed system. Implementation began in the summer of 2017, continued in 2018, and was completed in the summer of 2019. The team will return to Pusunchás in the summer of 2020 to close out the project.

Criticism of development projects has led to increased awareness of the importance of sustainability; however, when addressing sustainability, many small scale development projects do not consider the importance of an interdisciplinary approach, which is considered vital for longterm functionality. ${ }^{1}$ The nature of the EWB-Princeton subteam structure encourages the academically diverse student body to approach sustainability from a variety of fields and perspectives. As a result, the project has developed an interdependent and holistic approach to sustainability that carefully considers how the technical, financial, and social decisions of the project can ensure project longevity. Building upon existing approaches to sustainability, this paper argues for a three-pronged approach to development projects by analyzing the EWB- 
Princeton water system in Pusunchás and its implementation of technical, financial, and social tactics for sustainability.

\section{TEChNiCAL SUSTAINABILITY}

At the source of the Pusunchás gravity-fed water system, spring water is collected and filtered in a source capture box. From there, the water is carried through a 3-kilometer conduction line to a centralized 10,000-liter reservoir tank and is then distributed to individual households scattered throughout the six sectors of Pusunchás. All pipelines are constructed with Class-10 polyvinyl chloride (PVC) pipe and 250-liter pressure breaks are placed after every 80-meter drop in elevation. In August of 2018, nine out of eleven total planned pressure breaks were constructed along with 57 out of a total 64 tapstands, which provide each household with direct access to the water in the system. In August of 2019, the last two pressure breaks and seven tapstands were constructed, completing the system and providing an estimated 200 people with access to clean water. The tapstands, pressure breaks, and reservoir tank are all constructed with concrete reinforced with rebar and are outfitted with PVC valves. Structural integrity was analyzed using modeling software to account for unexpected loads, and the entire system was designed with extensive safety factors to ensure a long lifetime. Technical sustainability was reinforced through careful alternatives analysis of the source, community-informed pipeline design, the use of locallysourced materials, and practical measures to best protect the pipe.

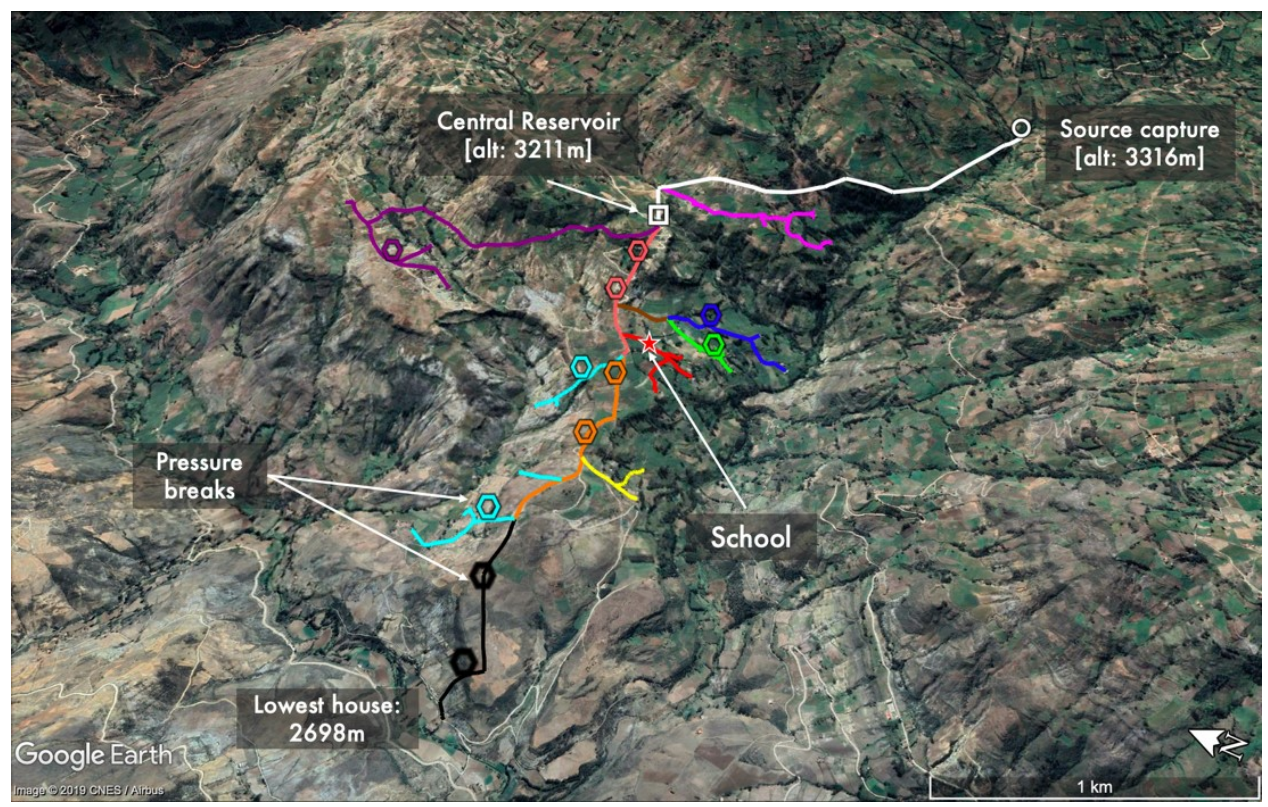

FIGURE 2

Google Earth Model of Pipeline Network

Given the constraints of local topography, the selection of an appropriate water source was one of the highest priorities and greatest challenges of the project. From a technical perspective, our choice methodology was based on elevation profile, source flow rate, and impact on other nearby 
communities. For the elevation profile, several of the prospective sources were located too close to the designed elevation of the reservoir tank. Based on hydraulic grade-line calculations, the water from these sources would not have reached the reservoir at an adequate rate.

Local climate presented further constraints on source selection. Flow rates exhibit extreme seasonal variability; the selected water source flow rate is four times larger in the wet season than in the dry season. To ensure that the network would remain full and that each person received an adequate supply of water, the source necessitated a steady year-round flow with dry season flow rates within the minimum community demand. This daily capacity is based on the Peruvian water usage standard of 20 liters per person per day, which is greater than the minimum standard from the World Health Organization at 15 liters per person per day. ${ }^{2}$ Designing the system with this capacity would safely meet the consumption demand of each individual household. It was thus important to establish the community expectation that water would not be used for irrigation or livestock, as the system would not be able to support both human consumption and agricultural use during the dry season. By designating the system only for potable use, the source may be more equally shared, and potential conflict associated with disproportionate irrigation usage may be avoided.

Another consideration for the source was the impact on neighboring communities. Given the region's heavy reliance on agriculture, any changes to mountain rivers or streams used for irrigation could negatively impact community members. As such, a requirement of the source was that it would not divert water from rivers or streams or flow into one of the primary rivers that the community depends on. Appropriate source selection relied on the institutional knowledge of the community to ensure that the decision would not inconvenience a single community member.

The final choice of source for the system reflected both the calculations made by our team of engineers and community insights on proper allocation of land and water resources. The finalized source originated at an elevation with sufficient head to fill the reservoir at a steady rate, held the necessary capacity for over 100 families, and avoided agricultural interference. After sampling and testing the water quality in a lab, the team deemed the source viable for consumption.

Pipeline branches were carefully designed to connect each sector of the community to the central reservoir tank in the most efficient manner. Desired flow rates were calculated based on population density and the Hazen-Williams equation was used to determine necessary pipe diameters. ${ }^{3}$ Due to the limited and often intermittent access to electricity, a key element of the system's design was the utilization of gravity as the only means of water transport. Avoiding the use of electric- or gasoline-powered pumps ensured consistent functionality and improved sustainability by reducing the need for additional system components. Moreover, the accompanying cost of fuel, operations, and maintenance of such components would have made joining the system cost-prohibitive for many families.

Pipeline routes were designed to minimize distances and optimize material use as well as to avoid roads, footpaths, and other areas susceptible to constant weathering or excess pressure. Any unforeseen physical obstacles such as large boulders or cliff faces were identified by community members and the route was adjusted appropriately. Collaborating with the community to find the best pipeline routes across farmland, forests, and rocky terrain as well as negotiating land rights for laying pipe has been a significant part of the in-country design process. 


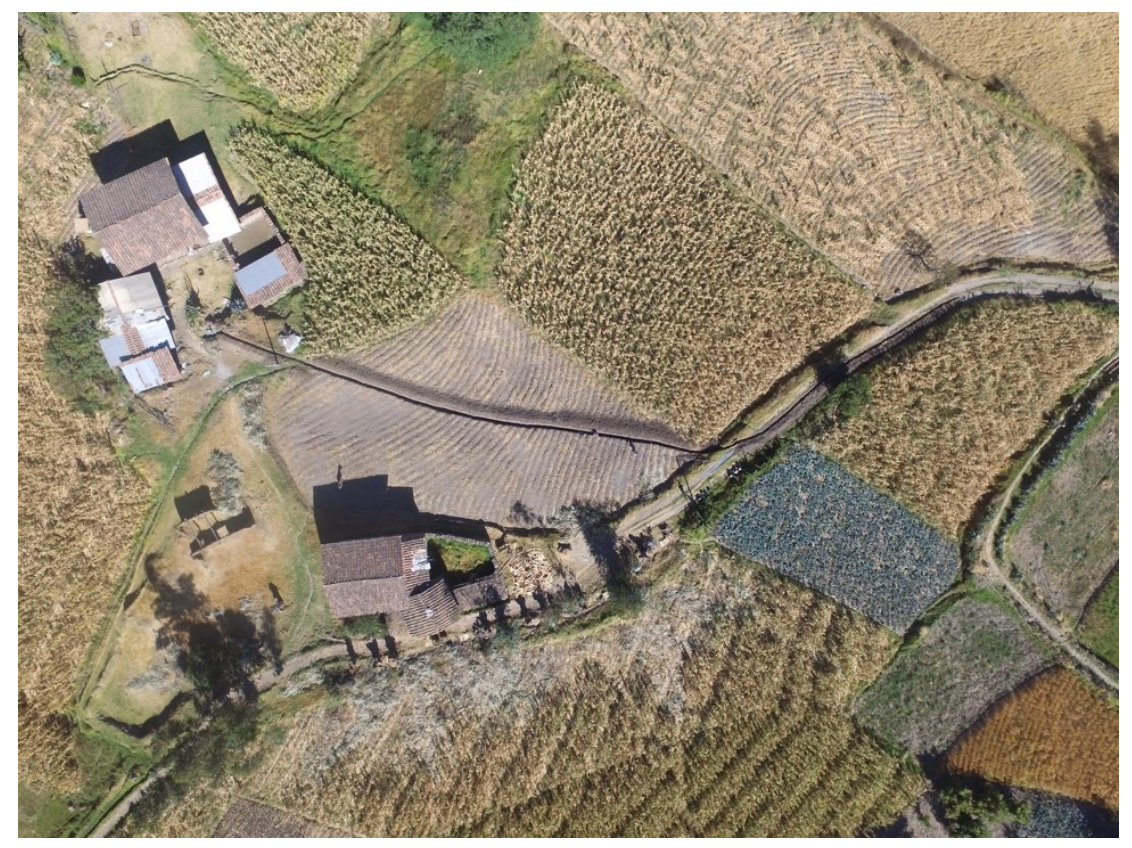

FIGURE 3

Domestic Pipeline Trench Through a Crop Field

One of the most important considerations for project materials was the availability of resources within the community. Prior to the 2017 Implementation Trip, Class-15 PVC pipe was chosen for all pipelines; this grade of pipe is able to withstand 15 bars of pressure and seemed technically viable. Given the pipe's specifications, the system was initially designed under the assumption that a pressure break would be necessary every 100 -meter change in elevation.

However, just a few months before the first Implementation Trip, it became apparent that Class-15 PVC pipe was only available in the city of Trujillo, a two-hour drive from Pusunchás. This limitation would make future maintenance logistically impractical. The EWB-Princeton team decided to switch to Class-10 PVC pipe, an alternative available for purchase in the nearby city of Otuzco. This design change required the construction of two additional pressure breaks, raising the cost of the project by around 1,000 USD, but significantly reducing any future logistical and financial difficulty for the community. Project redesign to use Class-10 PVC was a necessary decision to ensure that the community would be able to realistically maintain the system following the end of the partnership.

The final major consideration in the project's sustainable design was protection of the pipe. In steeper areas of the community, slope stability and pipe cover raised significant concerns during system implementation. Adequately covering PVC pipe with soil is vital to the lifetime of the system as it reduces pipe degradation caused by sunlight, exposure to the elements, and contact with humans and animals. Trenches excavated along cliff faces inevitably sent large amounts of soil tumbling downhill, leading to instability around the pipeline. One solution considered by the team was to encase the pipe in concrete to cement it in place and to provide a shield. However, while the concrete could protect the pipe from damage, it would also make repairs impossible, blocking access to the pipe. Additionally, temperature fluctuations due to the mountain climate 
would have caused eventually cement failure and potential pipe cracking as the cement would contract with cold weather.

Two alternative methods for protecting the PVC pipe were developed: sheathing the PVC pipe with galvanized pipe and planting local vegetation. Galvanized pipe serves as an extra barrier around the pipe, providing more structure, distributing heavy loads, and shielding the pipe from weathering, thus greatly reducing the frequency of system repairs. The local vegetation utilized is known to community members as penca, a cactus-like plant consisting of layers of stiff leaves with spikes. In the community, the plant is commonly used as a barrier to prevent animals from crossing into the road. This method was adopted by the team and community particularly in steeper sections to discourage people and animals from walking directly on top of pipelines while strengthening the protective soil cover. Such a simple but effective strategy to protect the pipeline significantly reduces the likelihood of degradation or breakage and encourages community engagement in the sustainability of the system. Through careful source selection, pipeline optimization, locally-sourced materials, and protective measures, the system has been designed and implemented to foster long-term sustainability.

\section{COMMUNITY-DRIVEN SUSTAINABILITY}

A three-part partnership was established between EWB-Princeton, the in-country NGO (Las Marianistas), and the community of Pusunchás. Representing the community is the local water committee known as the Junta Administrativa de Servicios Sanitarios (JASS). The JASS is composed of community members who are elected every four years. Their input and leadership is essential in every phase of the design process and they are heavily trained in implementation, operation, and maintenance to encourage future sustainability. Current JASS members have been present and involved since the beginning of the project in an effort to facilitate a smooth transition of knowledge once the project is finalized in 2020.

From the start, each of the three branches has held clearly defined roles and responsibilities. For EWB-Princeton, these roles are primarily technical: collecting data and measurements, creating technical designs, ordering materials, negotiating mason contracts, developing a user manual, and training the JASS in operations and maintenance. The NGO partner provides logistical support in-country, including housing, transportation, and support in purchasing materials and finding skilled labor. The JASS is responsible for all community relations, including negotiating land permissions, purchasing the source, organizing the community, collecting user dues, and fostering the partnership between community members and EWB-Princeton. Upon completion of the project, the community will maintain and upkeep the water system under the leadership of the JASS.

The first challenge to the partnership arose when political divisions within the community regarding land permissions halted implementation of the project. Construction of the pipeline required digging trenches, which often passed through neighboring land. However, some community members saw the opportunity to rekindle political feuds and refused to allow trenching through their land, denying water to their neighbors. In response, the JASS approached all parties, reminding them of the impact that such prolonged issues would have on the community as a whole. Since all households in the system draw water from the same reservoir tank, community trust and solidarity are integral to the success of the project and the ability to provide enough water for everyone. 
Community divisions were largely resolved by the JASS along with the help of Las Marianistas for legal support. EWB-Princeton offered assistance where possible, such as providing technical reasoning for the design of pipeline routes crossing through a community member's property. Though resolving internal political issues does not directly fall in the team's domain, consideration of community dynamics is imperative for informing design decisions and system construction. ${ }^{4}$ The team took these community aspects into consideration during the design of the project as well. The JASS will serve as the ultimate authority over usage of the water system and administrators will regulate usage through control of the valve boxes located upstream from each tapstand. If a household were to deliberately exceed the daily allotment of 20 liters per person per day, the JASS will have the power to limit or even cut off the flow to the tapstand for a period of time. The JASS will maintain access to the source capture, reservoir tanks, and pressure breaks, all of which are fenced and padlocked for security.

At annual community-wide meetings, the NGO Las Marianistas has reiterated the legal obligations associated with the project and explained the consequences should any member violate the terms of the user agreement. In a similar manner, EWB-Princeton has provided the technical expertise to help reduce tensions, explaining that the location of trenches for certain distribution lines as specified by the system design were non-negotiable, often because they were often the only technically viable option. It took a joint effort coordinated by the JASS, Las Marianistas, and EWB-Princeton to convince community members to set aside political differences for the communal benefit of implementing a working water system; thankfully, the unique dynamic between the organizations produced solutions to these political challenges.

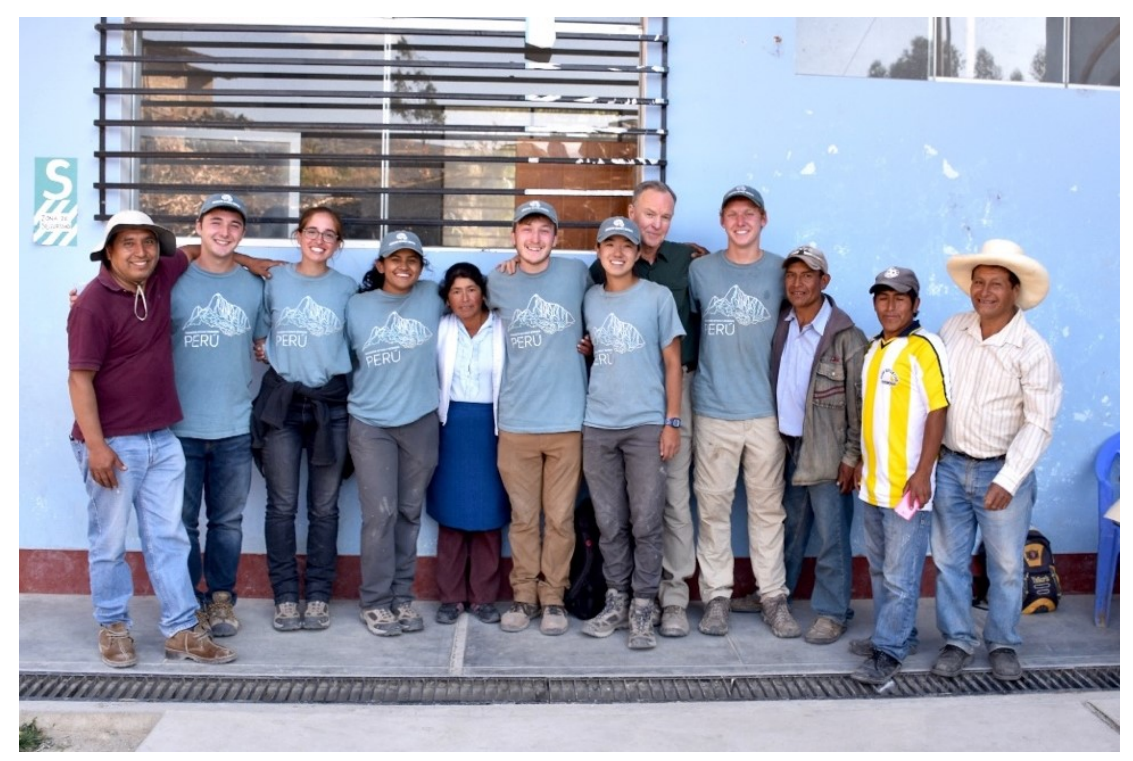

FIGURE 4

THE TEAm AND COMMUNITy LeAders DURING 2018 IMPLEMENTATION

To aid in establishing water usage guidelines, system operation, and technical maintenance, EWB-Princeton has developed a comprehensive system user manual. The manual includes protocols for flow disruptions, pipe breakage, and source capture box cleaning, providing detailed 
descriptions of system components for anticipated maintenance needs. The fundamental purpose of the user manual is to promote community accessibility by developing a sense of collective ownership amongst the members of the system through shared knowledge of the function and maintenance of the infrastructure.

In conjunction with this, it is paramount that the JASS in particular fully understands the fundamental structure of the system. EWB-Princeton has worked closely alongside JASS administrators and other community members during every implementation phase to help develop technical and problem-solving skills. Valves, elbow joints, unions, galvanized pipe, and other components have been inventoried with the JASS to expedite proper replacement and repairs. Design standards and technical choices were determined and properly communicated through meetings with the entire community as well as individual household visits to thoroughly engage each household on the network. The community's involvement in these decisions will facilitate a smooth transition towards a self-sustaining system once the project is complete.

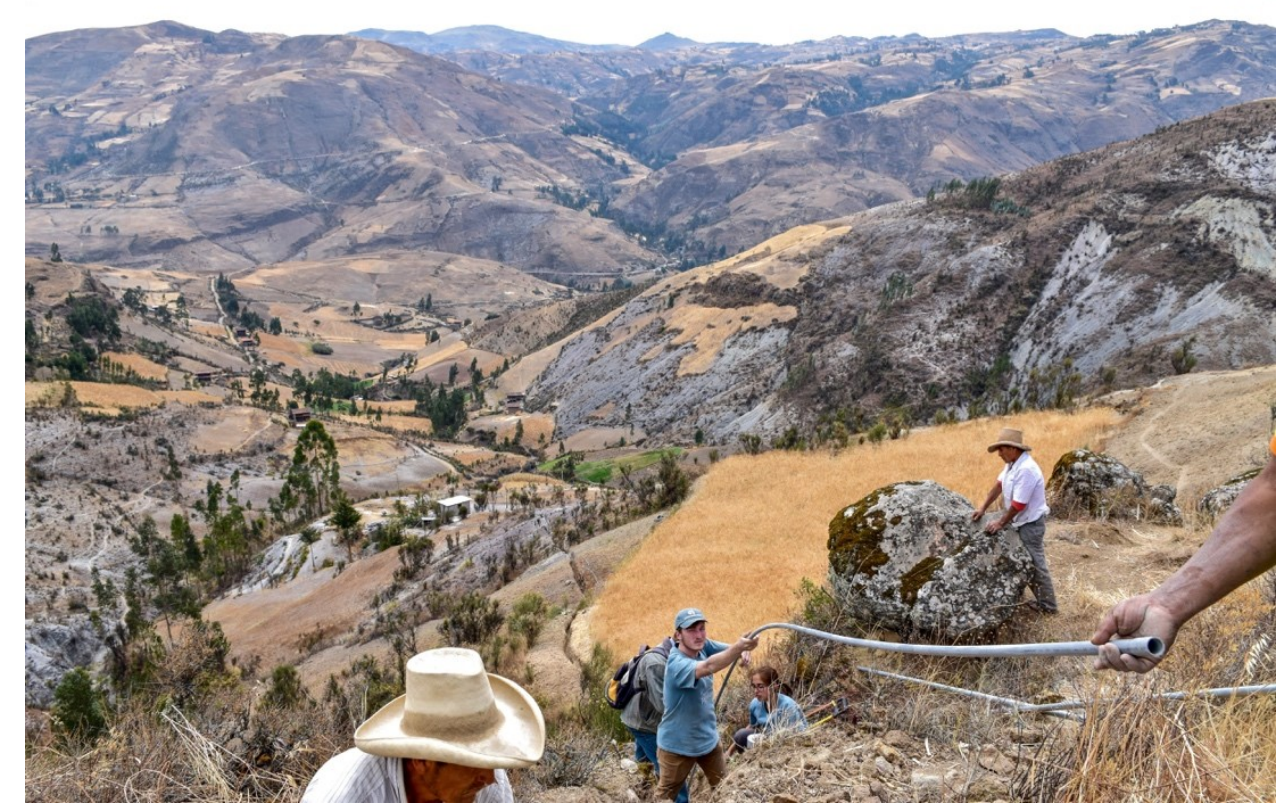

FIGURE 5

LAYing PiPe Down a Steep Cliff With the CoMmunity

When EWB-Princeton is not in-country for project implementation, frequent contact is maintained with Las Marianistas, the JASS, and community members often in the form of weekly online messaging, as some community members have recently acquired smartphones. In the weeks leading up to Implementation Trips, communication is critical for coordinating material purchases, logistical planning, and overall preparations for productive and efficient operations. The team regularly communicates with community members regarding developments in the project, the quality and delivery of water, and updates on everyday life in Pusunchás, strengthening the bond between EWB-Princeton and the community members. 
International Journal for Service Learning in Engineering, Humanitarian Engineering and Social Entrepreneurship

Vol. 14, No. 3, Special Issue, pp. 49-60, Fall 2019

ISSN 1555-9033

\section{SUSTAINABLE FinANCING}

In addition to time, one of the largest constraints for a project of this scale is funding. Minimizing long-term costs while avoiding comprises regarding technical aspects of the project has been one of the highest priority concerns for the team. The team has addressed this by obtaining locally sourced materials, optimizing the technical design, and preparing a thorough list of necessary materials prior to Implementation Trips. EWB-Princeton's close partnership with Las Marianistas has facilitated the efficient purchase of project materials from the local hardware store. Using easily accessible materials is an essential part of the project as it is more economical and practical for the community's long-term maintenance and repair. Las Marianistas ensures that the local hardware store stays consistent with the cost and availability of system components and even helped establish a buyback policy to return excess materials. The group also assists with transportation of materials via truck from the hardware store to the community at a significantly reduced cost.

EWB-Princeton has worked to minimize project costs through lifetime cost analysis of the entire system, ensuring that the community has the financial means necessary to maintain the system after the project is complete and the partnership has ended. Implementation of the five-year project is expected to total over one-hundred thousand USD, all of which EWB-Princeton covers through fundraising and sponsorships. In addition to technical design, one of the team's primary contributions is supporting the costs of project materials and hired labor over the course of the project lifetime. Projects through EWB-USA typically require the partner community to contribute $5 \%$ of total project expenses; however, this policy was waived for Pusunchás since the community members themselves provide all the necessary unskilled labor. The community's sole financial responsibilities are the purchase of the water source and maintenance costs following completion of the project implementation. Every month, the JASS collects dues from each user to fund system maintenance throughout the year. This financial structure promotes community ownership of the water system and ensures that the community will be self-sustaining in the future.

\section{Assessing Project Sustainability}

While overall project sustainability can only be accurately measured in the long term, evidence from the most recent Implementation Trip has demonstrated that the mechanisms for ensuring a successful and sustainable water system are well established. The community's technical competence, resolute leadership, and financial self-organization have created a sound foundation on which the future success of the system is secured. In the summer of 2019, the team evaluated all existing system structures alongside the JASS and found minimal need for repairs. The vast majority of users expressed their satisfaction with the functionality of their tapstands and water quality. A few faulty pipeline connections were identified; the technician of the JASS diagnosed each issue and prudently fixed them with locally-available components. The technician's responsibilities going forward are to routinely check the integrity of the pipeline and system structures, to conduct maintenance by cleaning pressure breaks and storage tanks, and to make repairs as necessary. Through project implementation experience, JASS training, and the user manual, the community is well-equipped with the tools to maintain and upkeep the water system. 


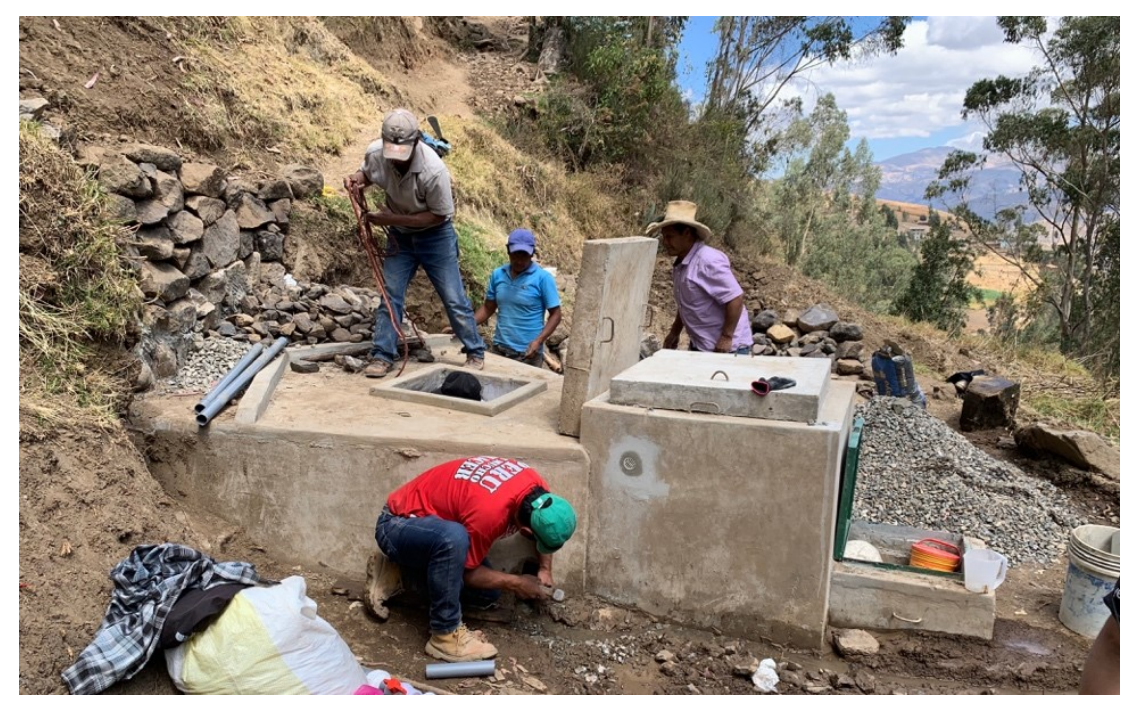

FIGURE 6

\section{MAKING REPAIRS AT THE SOURCE CAPTURE DURING 2019 IMPLEMENTATION}

During implementation in 2019, the JASS appeared visibly more comfortable with making assertive decisions in order to effectively manage the water system. Following internal disputes regarding the addition of a new user to the system, the JASS shut off the water for each of the users who refused to provide their neighbor with water access. The JASS advocates for sharing the water with all community members who contribute their share of labor and does not tolerate hostility or any such violations of the user agreement. By upholding accountability for each individual user, the JASS swiftly handled the dispute and ensured that all users benefit from the system.

The JASS has also already demonstrated that they are capable of successfully managing system maintenance funds. Each month, the JASS collects dues from system users to cover the expenses of maintenance and repairs. The JASS has also successfully enforced financial penalties in an effort to deter system misuse. Additionally, following the end of each fiscal year, any and all unused funds were successfully and equitably returned to system users. The JASS will continue to employ the same strategies as a means of funding the future of the water system, affirming the community's ownership and responsibility of their infrastructure.

Since the community is the ultimate owner and primary stakeholder of the water system, it is vital that they actively self-organize and enforce laws to support effective operation. Under the strong leadership of the JASS, the community now possesses the necessary tools and knowledge to best maintain the system for the long term. In the last couple of years of project implementation, the JASS has already exhibited great care and the ability to promote and uphold proper system usage.

\section{CONCLUSION}

At the foundation of a successfully implemented project as large as the Pusunchás water system is the core objective of long-term sustainability. This particular project presents a clear case study of the benefits of an interdisciplinary approach to sustainability, not only in the diversity of project aspects considered, but in the interconnectedness of the interdisciplinary solutions as well. 
Technical tactics such as choosing a reliable source, utilizing local resources, and designing for long term pipe protection allow for sustainable design while also assisting in financial sustainability by minimizing long term costs. Heavily training the community in operation and maintenance of the system strengthens the partnership and supports future functionality of the system. In this way, material and resource considerations, strong community relations, careful financial planning, and reliable partnerships have already begun to show early successes in longterm project sustainability as demonstrated by the final implementation trip in summer 2019. With all project stakeholders taking active roles, the community will be properly equipped with the tools, knowledge, and resources to properly maintain a safe and dependable water system for years to come.

\section{ACKNOWLEDGMENTS}

The Princeton Engineers Without Borders Peru Team would like to thank the community of Pusunchás and the JASS for their strong work ethic, collaboration, and dedication throughout the project. We would also like to thank our NGO partner Las Marianistas, most notably Julio Avalos Álvarez, whose insights and technical prowess proved to be an invaluable part of this project.

We would also like to acknowledge all past and current members of the EWB-Princeton chapter for their hard work throughout the academic year to make this project possible. We would like to recognize our technical mentors Russell Turner, Don Moris, Mike Galvin, Spencer Patterson, Josh Umansky-Castro and Corrie Kavanaugh as well as the EWB-USA organization as a whole for their guidance and continued support.

We also acknowledge the support that we have received from Princeton University, including Professor Peter Jaffe who serves as the team's faculty adviser. We thank the Princeton Environmental Institute, the Princeton University School of Engineering and Applied Science, and the Keller Center for Innovation in Engineering Education for their generous support. Finally, we thank our family and friends who have encouraged us at every step along the way.

1. Tulbure, Habil Ildiko, and Dumitru-Dorin Prunariu. 2018. Systems Engineering Approach For Getting Sustainability. International Multidisciplinary Scientific GeoConference : SGEM 18, (6): 713-720.

2. The Sphere Project, Humanitarian Charter and Minimum Standards in Disaster Response, (SCHR, 2001), 15.

3. Michael Mitchell, "Flow Loss in a Pressure Sewage Line," Journal of Environmental Health 50, no. 2 (1987): 85.

4. Muhammad, Sagheer Aslam, Mohammad Adil, Saeed Mirza M, and Dominic Frigon. 2016. Sustainable community-based drinking water systems in developing countries: Stakeholder perspectives. Journal of Water Supply : Research and Technology - AQUA 65, (5) (08): 407-416. 